\title{
Interleukin-35 as a predictor of prostate cancer in patients undergoing initial prostate biopsy
}

\author{
This article was published in the following Dove Press journal: \\ OncoTargets and Therapy \\ 14 July 2017 \\ Number of times this article has been viewed
}

\author{
Chenchao Zhou* \\ Jun Zhang* \\ Ye Chen \\ Hao Wang \\ Jianquan Hou \\ Department of Urology, The First \\ Affiliated Hospital of Soochow \\ University, Suzhou, People's \\ Republic of China \\ *These authors contributed equally \\ to this work
}

Correspondence: Jianquan Hou Department of Urology, The First Affiliated Hospital of Soochow University, I88 Shizi Rd, Suzhou 215006, People's Republic of China

Tel +8618906210606

Fax +8651265228072

Email houjianquan@suda.edu.cn
Background: Interleukin (IL)-35 is a novel inhibitory cytokine and has recently been implicated in tumor immunity. However, the role of IL-35 in prostate cancer (PCa) has not been elucidated.

Objective: To evaluate the role of plasma IL-35 in the diagnosis and prognosis of PCa in Chinese patients undergoing initial prostate biopsy.

Materials and methods: Using ELISA, plasma IL-35 levels were measured in 180 patients, who underwent a prostate biopsy. The clinical correlation of IL-35 with clinicopathological parameters was also evaluated. Univariate and multivariate logistic regression and receiver operating characteristic (ROC) curve analysis were performed to establish the role of IL-35 as a clinical biomarker.

Results: Seventy-five (41.6\%) of patients were histopathologically confirmed to have PCa. Plasma IL-35 levels were significantly higher in PCa patients $(134.48 \pm 78.48 \mathrm{pg} / \mathrm{mL})$ compared to non-PCa patients $(67.22 \pm 24.08 \mathrm{pg} / \mathrm{mL})$. ROC analysis showed that IL-35 was an independent predictor of PCa. Furthermore, IL-35 was found to be a significantly independent predictor of $\mathrm{PCa}$ in a group of patients with prostate-specific antigen levels between 4 and $10 \mathrm{ng} / \mathrm{mL}$; was also able to predict advanced PCa from localized PCa and bone metastasis positive PCa from negative PCa.

Conclusion: Our data suggest for the first time that plasma IL-35 levels are correlated with $\mathrm{PCa}$ and is the independent predictor of PCa progression and metastasis. Thus, IL-35 could be utilized as a potential biomarker for diagnosis and prognosis of $\mathrm{PCa}$, could also aid in decision making and predict the stage of the disease.

Keywords: IL-35, prostate cancer, prostate biopsy, diagnosis

\section{Introduction}

Prostate carcinoma ( $\mathrm{PCa}$ ) is one of the most common cancers among men, and there has been a significant increase in the incidence of PCa over the recent decades. ${ }^{1}$ The early detection and management of early-stage PCa are particularly important and challenging issues. Currently-used screening tests for PCa mainly include serum prostate-specific antigen (PSA) levels, digital rectal examination (DRE) and transrectal ultrasonography (TRUS), ${ }^{2}$ which play a significant role in the detection and staging of patients suffering from the disease. ${ }^{3}$ TRUS-guided biopsy of the prostate in patients with an elevated PSA and an abnormal finding on DRE, remains the gold standard for the detection of $\mathrm{PCa}$ and at least 10-12 biopsy cores are required. ${ }^{2}$ However, the sensitivity and specificity of TRUS-guided biopsy in the detection of PCa is low. Therefore, more reliable biomarkers that have a high specificity for the detection, diagnosis, and prognosis of PCa are desirable. 
More recently, evidence showed that the development and progression of urologic cancers are associated with an imbalance in the self-related immunity. ${ }^{4-6}$ Interleukin (IL)-35 belongs to IL-12 family of cytokines, which is a novel, responsive anti-inflammatory cytokine. ${ }^{7}$ IL-35 is a heterodimer comprised of the p35 subunit of IL-12 and EBI3 subunit of IL-27. ${ }^{8}$ IL-35 exhibits immunosuppressive effects and is primarily expressed by Foxp $3^{+}$regulatory T cells (Tregs). ${ }^{9}$ Recent studies have revealed that IL-35 is widely distributed and mediate its effects both in vivo and in vitro including an ability to suppress T-cell proliferation. ${ }^{7}$ Furthermore, IL-35 induces the conversion of conventional T-cells into an IL-35-expressing inducible Treg (iTr35 cells), which downregulate the development and differentiation of Th17 cell, ${ }^{10}$ and by which it suppress the progression of inflammatory diseases and autoimmune diseases. Recent studies have also discovered the role of IL-35 in inducing IL-10-producing regulatory B-cells (Breg-cells) and promote their conversion to IL- $35^{+}$Breg cells, which has a role in autoimmune diseases and cancer. ${ }^{11}$

Recently, gene expression analyses have suggested a broader tissue distribution of IL-35, including expression in cancer cells and Tregs. ${ }^{12}$ Further, the immunohistochemical analysis also revealed that EBI3 and p35 are highly expressed in placental trophoblasts and tumor tissues from lung cancer, colon cancer, esophageal carcinoma, hepatocellular carcinoma, and cervical carcinoma. ${ }^{13,14}$ Taken together, these findings suggest that IL-35 plays a critical role in tumor development and progression. In tumor microenvironment, Foxp $3^{+}$Tregs and other Tregs are considered to be the primary producer of IL-35, ${ }^{15}$ and IL-35 has also been found to promote the suppression of Th1, Th17 and Th 2 cells. ${ }^{10}$ The IL-35 expression has been associated with immunosuppression, tumor progression, and poor prognosis. Previous studies have also shown the correlation of EBI3 expression with poor prognosis of human lung cancer. ${ }^{16}$ Moreover, by enhancing myeloid cells accumulation in the tumor microenvironment, tumor-cell derived IL-35 promotes tumor growth, as well as tumor angiogenesis. ${ }^{17}$ Though, Olson et al reported that human prostate tumor antigen-specific Tregs can be inhibited by IL-35 blockade. ${ }^{18}$ However, to the best of our knowledge, the clinical correlation of IL-35 and clinicopathological parameters of PCa has not been established.

The present study was initiated to investigate the role of plasma IL-35 levels in distinguishing PCa from non-PCa, and also to determine plasma IL-35 levels in patients who underwent initial prostate biopsy. Further, the plasma IL-35 levels were analyzed and correlated with clinicopathological parameters to evaluate its role as a potential biomarker in $\mathrm{PCa}$.

\section{Materials and methods Study subjects}

One hundred and eighty patients who underwent initial TRUS-guided prostate biopsy at the First Affiliated Hospital of Soochow University, from January 2015 to December 2015 were enrolled for the present study. Patients with autoimmune or inflammatory diseases, secondary or multiple malignancies and drug treatment for benign prostatic hyperplasia $(\mathrm{BPH})$ were excluded from the study. Written informed consent was obtained from all patients. The study was approved by the Ethics Committees of Soochow University.

\section{Sample collection and processing}

Blood samples $(3 \mathrm{~mL})$ were collected early morning after an overnight (12 h) fast using EDTA tubes, before any treatment. None of the patients had received biopsy, surgery, chemotherapy, or radiotherapy before blood collection. All blood samples were processed within $2 \mathrm{~h}$ of collection. Plasma samples were isolated by centrifugation for $15 \mathrm{~min}$ at $1,200 \mathrm{~g}$, then transferred to new tubes and stored at $-80^{\circ} \mathrm{C}$.

\section{ELISA analysis}

The plasma levels of IL-35 in patients' samples were analyzed using human IL-35 ELISA kit (Cloud-Clone Corp, Wuhan, People's Republic of China), according to manufacturer's protocol. Samples were assayed in duplicate.

\section{Transrectal ultrasound guided prostate biopsy}

Ultrasound consisted of grayscale and color Doppler imaging using a Sequoia 512 unit with a convex $8 \mathrm{MHz}$ transrectal probe (Siemens, Munich, Germany). All prostate biopsies were performed following a 12-core scheme using $18 \mathrm{G}$ automatic core biopsy needle (CR Bard Inc., Govington, GA, USA). When a hypoechoic area or suspicious lesion was noted under ultrasound, one or two additional cores were also collected. Clinicopathological characteristics of the patients including PSA, total prostate volume, prostate specific antigen density, tumor node metastasis (TNM) stage, histological grade and age at diagnosis were obtained from medical records.

\section{Statistical analysis}

All the statistical analyses were performed using SPSS V19.0 software (IBM Corporation, Armonk, NY, USA) and GraphPad5 (GraphPad Software, La Jolla, CA, USA). 
Data are presented as the mean \pm standard deviation (SD). Using $\chi^{2}$ test, the differences between the clinicopathological characteristics of the PCa and the non-PCa group were compared. Continuous variables were measured by KolmogorovSmirnov for testing the fitting of data to normal distribution. Student's $t$-test was used for parametric data and MannWhitney test for non-parametric data. Significance between groups was evaluated by ANOVA. Two-sided $P$-values were calculated, and $P<0.05$ was considered as statistically significant. Important variables were then subjected to multivariate logistic regression analyses. Then a receiver operating characteristic (ROC) curve analysis was applied and area under curve (AUC) was calculated to determine the predictive value of each independent variable.

\section{Results}

\section{Basic clinicopathological characteristics of patients}

According to the histopathologic examinations, 75 (41.6\%) of 180 patients were diagnosed with PCa and 105 (58.4\%) patients were non-PCa. The comparisons between the two groups are presented in Table 1. Plasma IL-35 levels were significantly higher in $\mathrm{PCa}$ patients than non-PCa patients $(134.48 \pm 78.48$ vs $67.22 \pm 24.08 \mathrm{pg} / \mathrm{mL}, P<0.001$; Figure 1A). In addition, the significant differences of serum

Table I Clinical characteristics of $\mathrm{PCa}$ patients and non-PCa patients

\begin{tabular}{|c|c|c|c|}
\hline \multirow[t]{2}{*}{ Variables } & \multicolumn{2}{|c|}{ Biopsy outcomes } & \multirow[t]{2}{*}{$P$-value } \\
\hline & PCa patients & $\begin{array}{l}\text { non-PCa } \\
\text { patients }\end{array}$ & \\
\hline Subject, N & 75 (4I.6\%) & 105 (58.4\%) & - \\
\hline Age, years & $70 \pm 7.49$ & $63 \pm 7.96$ & $<0.00 \mathrm{I}$ \\
\hline $\mathrm{BMI}, \mathrm{kg} / \mathrm{m}^{2}$ & $23.8 \mathrm{I} \pm 2.72$ & $23.62 \pm 3.68$ & 0.971 \\
\hline $\mathrm{PSA}, \mathrm{ng} / \mu \mathrm{L}$ & $51.94 \pm 8.610$ & $13.46 \pm 1.010$ & $<0.00$ I \\
\hline $\mathrm{TPV}, \mathrm{mL}$ & $49.03 \pm 31.2$ & $49.45 \pm 24.8$ & 0.57 \\
\hline IL-35, pg/mL & | $34.48 \pm 78.48$ & $67.22 \pm 24.08$ & $<0.00$ I \\
\hline \multicolumn{4}{|c|}{ Stage at diagnosis, $\mathrm{n}$} \\
\hline I & 4 & - & - \\
\hline II & 41 & - & - \\
\hline III & 23 & - & - \\
\hline IV & 7 & - & - \\
\hline MO & 26 & - & - \\
\hline MI & 22 & - & - \\
\hline \multicolumn{4}{|c|}{ Gleason score (n) } \\
\hline$\leq 6$ & 6 & - & - \\
\hline$=7$ & 19 & - & - \\
\hline$\geq 8$ & 50 & - & - \\
\hline
\end{tabular}

Notes: Data are shown as mean \pm standard deviation. " - " = no data. Abbreviations: BMI, body mass index; IL, interleukin; PCa, prostate cancer; PSA, prostate-specific antigen; PSAD, prostate specific antigen density; TPV, total prostate volume.
PSA levels (51.94 \pm 8.61 vs $13.46 \pm 1.01 \mathrm{ng} / \mu \mathrm{L}, P<0.001)$ and age ( $70 \pm 7.49$ vs $63 \pm 7.96$ years, $P<0.001$ ), were observed between the two groups.

\section{Correlation of IL-35 and clinicopathological characteristics}

The significantly associated clinicopathological parameters including PSA, plasma IL-35 levels and age between the $\mathrm{PCa}$ and non-PCa patients are presented in Table 2. These parameters were further analyzed using logistic regression analysis. The result of univariate analysis showed that $\mathrm{PCa}$ was significantly associated with IL-35 $(P<0.001)$, PSA $(P<0.001)$ and age $(P<0.001)$. The result of multivariate analysis showed that IL-35, PSA, and age were independent factors in predicting the presence of $\mathrm{PCa}(P<0.05)$. Area under ROC curve (AUC) of IL-35 was significantly higher than PSA (AUC $=0.820$ vs $0.703, P<0.05$; Figure $2 \mathrm{~A}$ ), the sensitivity was $77.3 \%$, specificity was $73.3 \%$, and diagnostic accuracy was $78.3 \%$. When we combined IL-35 and PSA as PCa predictor, diagnostic efficiency had a remarkable improvement ( $\mathrm{AUC}=0.879$ vs 0.820 or 0.703 , $P<0.05$; Figure 3 ), the sensitivity was $80.3 \%$, specificity was $85.7 \%$.

Moreover, patients with PSA levels of $4-10 \mathrm{ng} / \mathrm{mL}$ were also classified into two groups. In Group I of 57 men, a significant difference was found between IL-35 and PSA for the detection of PCa. At the best the cut-off values of $78.7 \mathrm{pg} / \mathrm{mL}$, the sensitivity, specificity and diagnostic accuracy of IL-35 were $71.4 \%, 66.4 \%$ and $83.9 \%$, respectively. A statistically significant difference was observed between IL-35 and PSA in the diagnosis of PCa (AUC 0.78 vs 0.54 , $P<0.05$; Figure 2B).

\section{Association of IL-35 and PCa stage}

Based on the standard for TNM stage, PCa patients were classified into two groups: localized PCa patients (stage I-II, $\mathrm{n}=45$ ) and advanced PCa patients (stage III-IV, $\mathrm{n}=30$ ). As illustrated in Figure 1B, plasma IL-35 levels in advanced $\mathrm{PCa}$ patients were significantly higher than in the localized PCa $(164.57 \pm 116.82$ vs $95.38 \pm 53.52 \mathrm{pg} / \mathrm{mL}, P<0.01)$. ROC analysis showed that plasma IL-35 level was the better predictor of advanced PCa than PSA (AUC 0.757 vs 0.709 , $P<0.05$; Figure 2C). At the cutoff value of $88.9 \mathrm{pg} / \mathrm{mL}$, IL-35 could effectively discriminate advanced $\mathrm{PCa}$ with a sensitivity of $80.6 \%$, a specificity of $64 \%$ and a diagnostic accuracy of $73.9 \%$.

In the present study, a total of 48 PCa patients underwent bone scan analysis, and $22(45.83 \%)$ of them were 

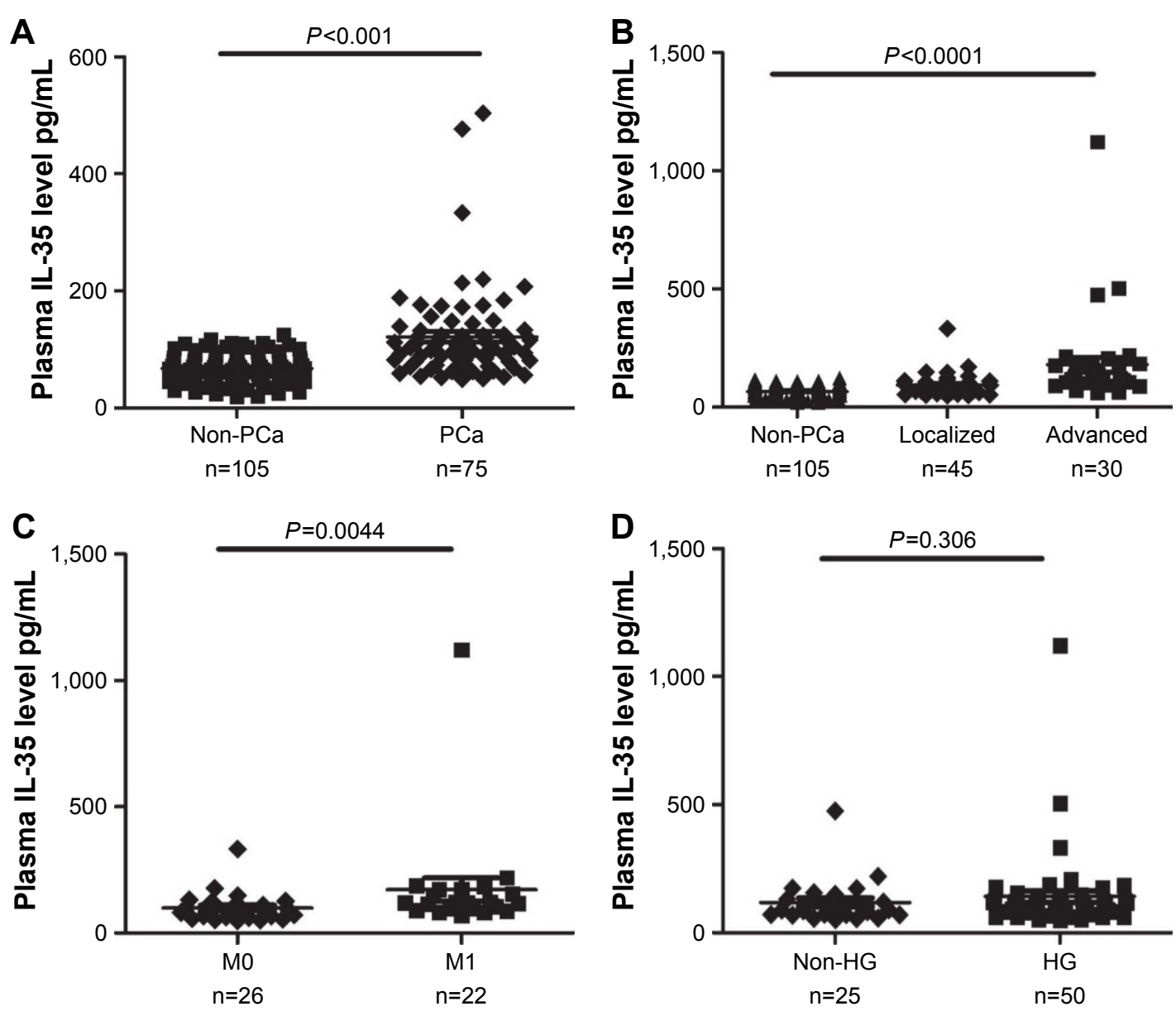

Figure I (A) Plasma IL-35 levels between PCa and non-PCa patients. (B) Plasma levels of IL-35 among non-PCa patients, localized PCa and advanced PCa (C) Plasma IL-35 levels in bone metastasis positive patients (MI) and negative patients (M0). (D) Plasma IL-35 levels between HG and non-HG PCa patients.

Abbreviations: PCa, prostate cancer; IL, interleukin; HG, high grade.

found to be positive for bone metastasis, and as expected, the plasma IL-35 levels were significantly higher in bone metastasis positive patients than the negative bone metastasis patients (172.36 146.02 vs $99.65 \pm 57.52 \mathrm{pg} / \mathrm{mL}$; Figure 1C), and the ROC analysis showed that plasma IL-35 levels (AUC 0.741) were the better predictor than PSA (AUC 0.694; Figure 2D).

\section{Correlation of IL-35 and Gleason score of $\mathrm{PCa}$}

On the basis of the Gleason score, PCa patients were again classified into two groups, high grade (HG; Gleason

Table 2 Univariate and multivariate analysis for prognostic factors in patients with $\mathrm{PCa}$

\begin{tabular}{|c|c|c|c|c|c|c|}
\hline \multirow[t]{2}{*}{ Variable } & \multicolumn{3}{|c|}{ Univariate } & \multicolumn{3}{|c|}{ Multivariate } \\
\hline & OR & $95 \% \mathrm{Cl}$ & $P$-value & OR & $95 \% \mathrm{Cl}$ & $P$-value \\
\hline Age & 1.128 & $1.077-1.181$ & $<0.001$ & 1.133 & $1.061-1.209$ & $<0.001$ \\
\hline PSA & 1.053 & $|.026-1.08|$ & $<0.001$ & 1.041 & $1.013-1.070$ & 0.003 \\
\hline IL-35 & 1.047 & $1.032-1.062$ & $<0.001$ & 1.047 & $1.029-1.065$ & $<0.001$ \\
\hline
\end{tabular}

Abbreviations: PSA, prostate-specific antigen; PCa, prostate cancer; IL, interleukin. score $\geq 8, \mathrm{n}=50$ ) and non-high grade (non-HG, Gleason score $\leq 7, \mathrm{n}=25)$. Interestingly, no significant difference was observed for IL-35 ( $P=0.306$; Figure 1D) when PSA showed a significant difference between the two groups $(P<0.05)$.

\section{Discussion}

IL-35, the most recently identified member of the IL-12 family, and similar to other members of the IL-12 family (including IL-12, IL-23, and IL-27), IL-35 is composed of a heterodimer of $\alpha$ and $\beta$ chains. ${ }^{7}$ IL-12 comprised of $\mathrm{p} 35$ and $\mathrm{p} 40$ subunits, while, IL-27 has been identified to consist of EBI3 subunits and p28 subunits. IL-35 plays important role in anti-inflammatory responses and has been associated with reduced graft-versus-host diseases (GVHDs) from allogeneic hematopoietic stem cell transplantation (allo-HSCT) and autoimmune diseases. ${ }^{19,20}$ More recently, IL-35 has been recognized to play a significant role in the pathogenesis of tumors, progression and prognosis and tumor derived IL-35 has been confirmed to promote tumor progression in two tumor models, including plasmacytoma and B16 melanoma. ${ }^{17}$ 
A

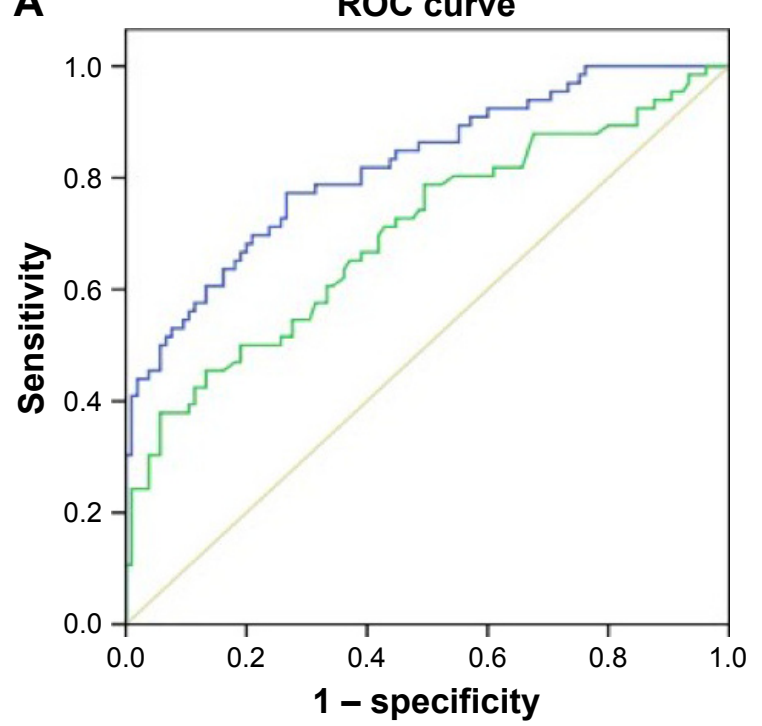

C

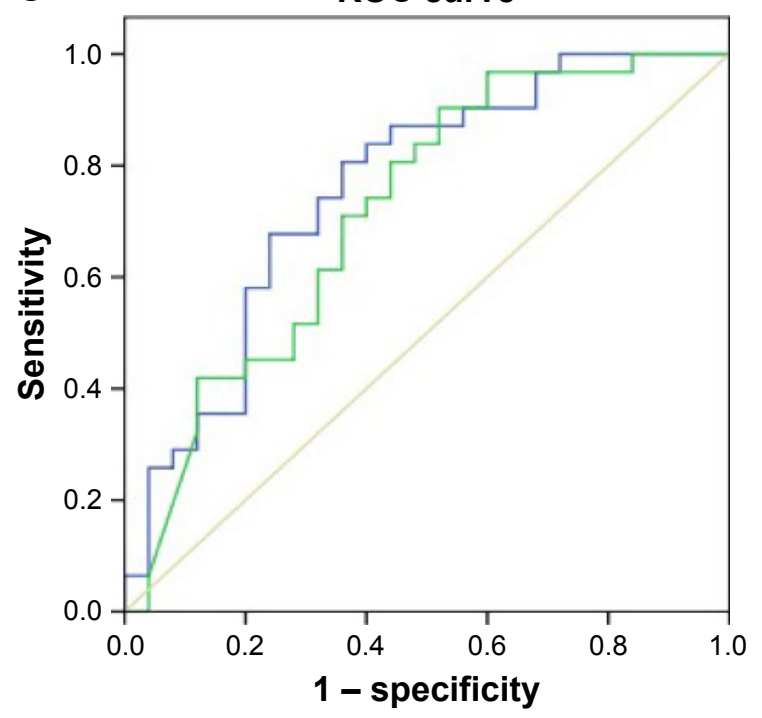

B

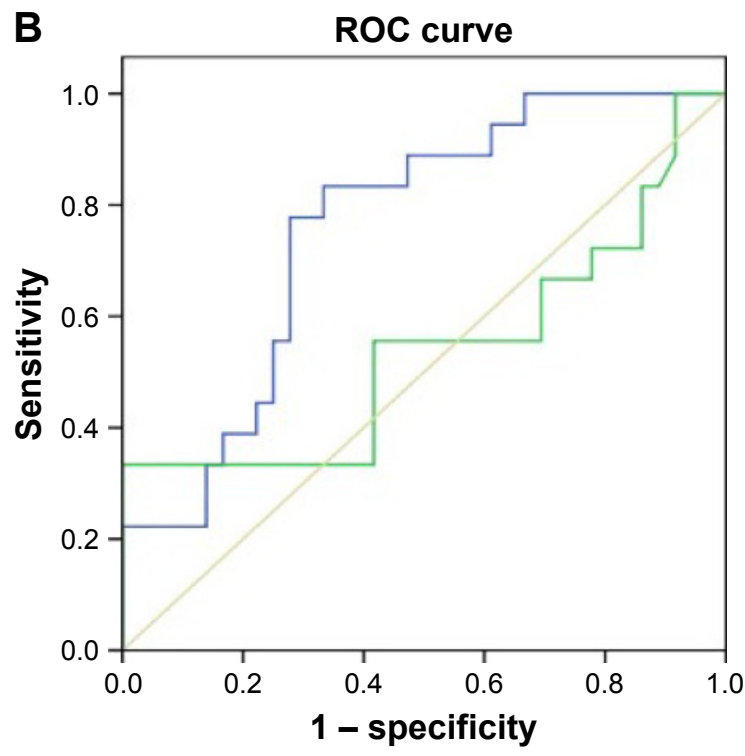

D

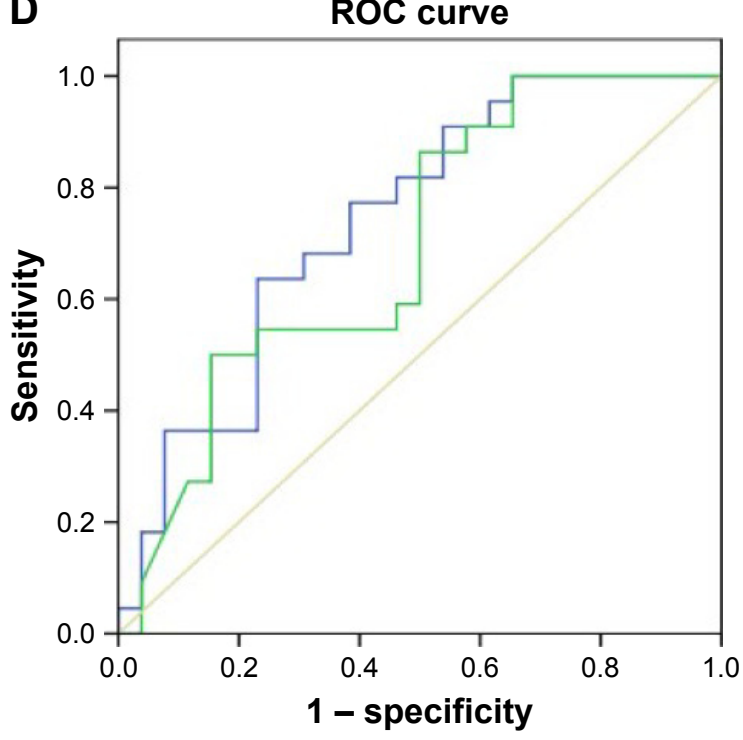

Source of the curve

- IL-35 - PSA Reference line

Figure 2 (A) ROC curve analysis of IL-35 and PSA between PCa and non-PCa patients. (B) ROC curve analysis of IL-35 and PSA patients with PSA levels of 4 to I0 ng/mL. (C) ROC curve analysis of IL-35 and PSA, to discriminate advanced PCa patients from localized PCa patients. (D) ROC curve analysis using IL-35 and PSA, to discriminate positive bone metastasis patients from negative bone metastasis patients.

Abbreviations: PCa, prostate cancer; IL, interleukin; ROC, receiver operating characteristic; PSA, prostate-specific antigen.

In addition, the expression of IL-35 has been associated with tumor progression as well as poor prognosis. However, the role of IL-35 in prostate tumorigenesis, progression, and prognosis, remains to be elucidated.

To the best of our knowledge, the present study provides the first report on the significant association of increased plasma IL-35 levels in histopathologically confirmed patients of $\mathrm{PCa}$ in comparison to non-PCa patients. The ROC curve indicated that high plasma IL-35 levels $(81.3 \mathrm{pg} / \mathrm{mL})$ could effectively predict the presence of PCa. ROC curves were compared to significantly discriminate the effect of PSA and plasma IL-35 levels. The results indicated that plasma levels of IL-35 are a better predictor than serum PSA levels in discriminating PCa patients especially when the levels of PSA is between 4 and $10 \mathrm{ng} / \mathrm{mL}$.

Moreover, we found that in advanced PCa patients, the concentration of IL-35 in plasma was significantly higher than in localized PCa patients, which indicate IL-35 a better predictor in discriminating advanced from localized $\mathrm{PCa}$ patients. However, plasma levels of IL-35 were not found to 


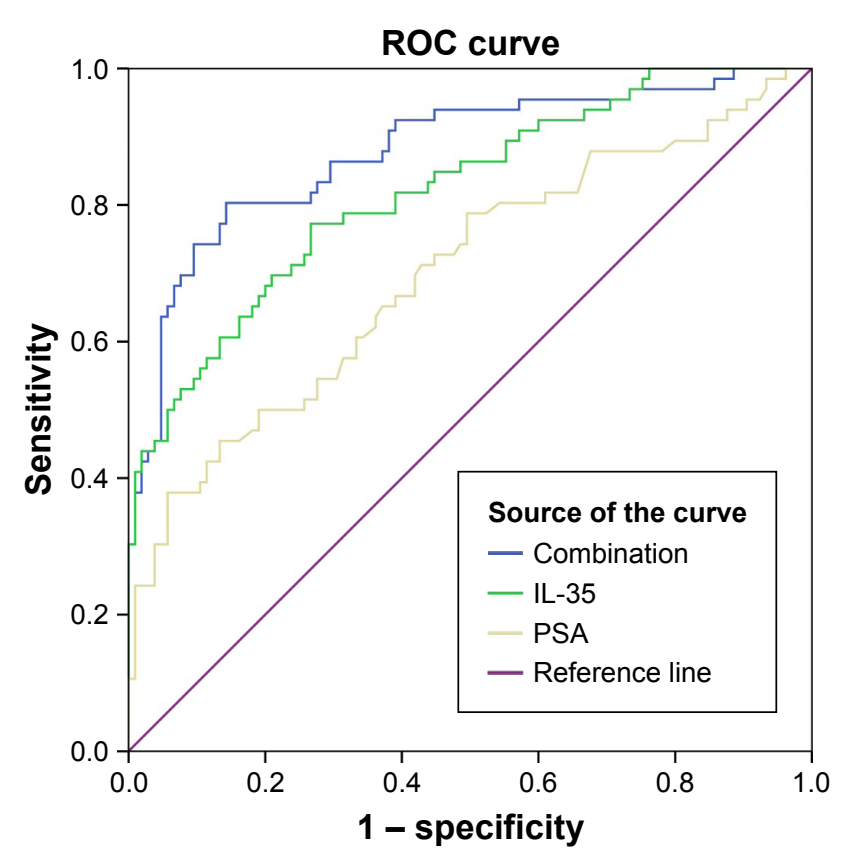

Figure 3 IL-35+ PSA combination as prostate cancer predictor.

Abbreviations: IL, interleukin; ROC, receiver operating characteristic; PSA, prostate-specific antigen.

be associated with Gleason scores, and only a trend towards higher Gleason scores was observed, which may be attributed to a lower number of PCa patients in the study.

Previous studies have suggested that IL-35 is a member of Tregs cytokine family and is required for their function. In vivo, IL-35 is mainly expressed by Tregs and promotes the differentiation of naïve T cells into IL-35 induced Tregs (iTr35 cells). ${ }^{7,9,10}$ Furthermore, gene expression analysis revealed that IL-35 have a broader tissue distribution. EBI3 was detected in Hodgkin lymphoma cells and acute myeloid leukemia cells. ${ }^{21,22}$ Thus, we believe that IL-35 not only mediates the biological function of Tregs but also contributes to the tumor microenvironment. More recently, human prostate tumor antigen-specific $\mathrm{CD} 8^{+}$Treg cells were found to be inhibited by CTLA- 4 or IL-35 blockade. ${ }^{18}$ Turnis et a ${ }^{23}$ further suggested that IL-35 limits anti-tumor immunity. However, contradictory results have also been reported. ${ }^{13}$ Therefore, further studies on the immunological mechanisms of IL-35 in PCa are desired.

In the present study, plasma IL-35 levels were found to be significantly positively associated with tumor stage and bone metastasis, two important indicators of poor outcomes. Given the roles of IL-35 in protecting tumor cells against immunity, these evidences further support our hypothesis that IL-35 might promote the progression of PCa. Furthermore, higher levels of IL-35 in the tumor microenvironment are likely to play a significant role in PCa progression and metastasis.
This is consistent with the previous findings on other carcinomas. ${ }^{24-27}$ Therefore, monitoring IL-35 levels could aid in medical decision making among Chinese men undergoing a prostate biopsy and may save unnecessary biopsies.

The present study does have its own limitations and strengths. The major limitation of the present study is the small sample size. Also, lack of tissues samples for the examination of IL-35 made it difficult to elucidate the mechanism of IL-35 in the tumor microenvironment. However, the present study was first to show the association of plasma IL-35 with $\mathrm{PCa}$ progression and metastasis.

\section{Conclusion}

Plasma levels of IL-35 were significantly higher in PCa patients, also higher plasma IL-35 levels were positively associated with advanced stage of $\mathrm{PCa}$, indicating that plasma IL-35 is a predictable indicator which could aid in decision making among patients undergoing an initial prostate biopsy.

\section{Acknowledgment}

This study was supported by the National Natural Science Foundation of China (grants 81500572 and 81272839).

\section{Disclosure}

The authors report no conflicts of interest in this work.

\section{References}

1. Ferlay J, Shin HR, Bray F, Forman D, Mathers C, Parkin DM. Estimates of worldwide burden of cancer in 2008: GLOBOCAN 2008. Int J Cancer. 2010;127(12):2893-2917.

2. Heidenreich A, Aus G, Bolla M, et al. EAU guidelines on prostate cancer. Eur Urol. 2008;53(1):68-80. Available from: https://www.ncbi.nlm.nih. gov/pubmed/?term=17920184. Accessed June 22, 2017.

3. Pallwein L, Mitterberger M, Pelzer A, et al. Ultrasound of prostate cancer: recent advances. Eur Radiol. 2008;18(4):707-715.

4. Sankhwar M, Sankhwar SN, Abhishek A, Rajender S. Clinical significance of the VEGF level in urinary bladder carcinoma. Cancer Biomark. 2015;15(4):349-355.

5. Montironi R, Santoni M, Sotte V, et al. Emerging Immunotargets and Immunotherapies in Prostate Cancer. Curr Drug Targets. 2016;17(7): 777-782.

6. Leclerc BG, Charlebois R, Chouinard G, et al. CD73 Expression Is an Independent Prognostic Factor in Prostate Cancer. Clin Cancer Res. 2016;22(1):158-166.

7. Collison LW, Workman CJ, Kuo TT, et al. The inhibitory cytokine IL-35 contributes to regulatory T-cell function. Nature. 2007;450(7169): $566-569$.

8. Devergne O, Birkenbach M, Kieff E. Epstein-Barr virus-induced gene 3 and the p35 subunit of interleukin 12 form a novel heterodimeric hematopoietin. Proc Natl Acad Sci U S A. 1997;94(22):12041-12046.

9. Niedbala W, Wei XQ, Cai B, et al. IL-35 is a novel cytokine with therapeutic effects against collagen-induced arthritis through the expansion of regulatory T cells and suppression of Th17 cells. Eur J Immunol. 2007;37(11):3021-3029. 
10. Collison LW, Chaturvedi V, Henderson AL, et al. IL-35-mediated induction of a potent regulatory T cell population. Nat Immunol. 2010; 11(12):1093-1101.

11. Wang RX, Yu CR, Dambuza IM, et al. Interleukin-35 induces regulatory B cells that suppress autoimmune disease. Nat Med. 2014; 20(6):633-641.

12. Li X, Mai J, Virtue A, et al. IL-35 is a novel responsive anti-inflammatory cytokine - a new system of categorizing anti-inflammatory cytokines. PLoS One. 2012;7(3):e33628.

13. Long J, Zhang X, Wen M, et al. IL-35 over-expression increases apoptosis sensitivity and suppresses cell growth in human cancer cells. Biochem Biophys Res Commun. 2013;430(1):364-369.

14. Mao H, Gao W, Ma C, et al. Human placental trophoblasts express the immunosuppressive cytokine IL-35. Hum Immunol. 2013;74(7): 872-877.

15. Liyanage UK, Moore TT, Joo HG, et al. Prevalence of regulatory $\mathrm{T}$ cells is increased in peripheral blood and tumor microenvironment of patients with pancreas or breast adenocarcinoma. J Immunol. 2002; 169(5):2756-2761.

16. Nishino R, Takano A, Oshita H, et al. Identification of Epstein-Barr virus-induced gene 3 as a novel serum and tissue biomarker and a therapeutic target for lung cancer. Clin Cancer Res. 2011;17(19): 6272-6286.

17. Wang Z, Liu JQ, Liu Z, et al. Tumor-derived IL-35 promotes tumor growth by enhancing myeloid cell accumulation and angiogenesis. J Immunol. 2013;190(5):2415-2423.

18. Olson BM, Jankowska-Gan E, Becker JT, Vignali DA, Burlingham WJ, McNeel DG. Human prostate tumor antigen-specific CD8+ regulatory T cells are inhibited by CTLA-4 or IL-35 blockade. J Immunol. 2012;189(12):5590-5601.
19. Liu Y, Wu Y, Wang Y, et al. IL-35 mitigates murine acute graft-versushost disease with retention of graft-versus-leukemia effects. Leukemia. 2015;29(4):939-946.

20. Olson BM, Sullivan JA, Burlingham WJ. Interleukin 35: a key mediator of suppression and the propagation of infectious tolerance. Front Immunol. 2013;4:315.

21. Niedobitek G, Pazolt D, Teichmann M, Devergne O. Frequent expression of the Epstein-Barr virus (EBV)-induced gene, EBI3, an IL-12 p40-related cytokine, in Hodgkin and Reed-Sternberg cells. J Pathol. 2002;198(3):310-316.

22. Poleganov MA, Bachmann M, Pfeilschifter J, Muhl H. Genome-wide analysis displays marked induction of EBI3/IL-27B in IL-18-activated AML-derived KG1 cells: critical role of two kappaB binding sites in the human EBI3 promotor. Mol Immunol. 2008;45(10):2869-2880.

23. Turnis ME, Sawant DV, Szymczak-Workman AL, et al. Interleukin-35 Limits Anti-Tumor Immunity. Immunity. 2016;44(2):316-329.

24. Zhang Y, Sun H, Wu H, Tan Q, Xiang K. Interleukin 35 is an independent prognostic factor and a therapeutic target for nasopharyngeal carcinoma. Contemp Oncol (Pozn). 2015;19(2):120-124.

25. Jin P, Ren H, Sun W, Xin W, Zhang H, Hao J. Circulating IL-35 in pancreatic ductal adenocarcinoma patients. Hum Immunol. 2014;75(1): 29-33.

26. Zeng JC, Zhang Z, Li TY, et al. Assessing the role of IL-35 in colorectal cancer progression and prognosis. Int J Clin Exp Pathol. 2013;6(9): 1806-1816.

27. Gu X, Tian T, Zhang B, et al. Elevated plasma interleukin-35 levels predict poor prognosis in patients with non-small cell lung cancer. Tumour Biol. 2015;36(4):2651-2656.
OncoTargets and Therapy

\section{Publish your work in this journal}

OncoTargets and Therapy is an international, peer-reviewed, open access journal focusing on the pathological basis of all cancers, potential targets for therapy and treatment protocols employed to improve the management of cancer patients. The journal also focuses on the impact of management programs and new therapeutic agents and protocols on

\section{Dovepress}

patient perspectives such as quality of life, adherence and satisfaction. The manuscript management system is completely online and includes a very quick and fair peer-review system, which is all easy to use. Visit http://www.dovepress.com/testimonials.php to read real quotes from published authors. 